\title{
EL INSTITUTO NACIONAL DE INDUSTRIA: UNA HISTORIA ECONOMICA
}

\author{
LUIS RODRIGUEZ ROMERO \\ Universidad Carlos III
}

En sus cincuenta años de existencia (1941-1991) el INI ha ido acumulando una densa y variopinta biografia que, entre otras connotaciones, le configura como un protagonista destacado de la evolución de la economía española y, más especificamente, de su industria, a través de las diversas etapas que componen dicho periodo. Su carácter complejo y poliédrico le confiere, asimismo, una interesante característica, como es su capacidad reflectante de los intereses y preocupaciones de cualquier analista que a él se aproxima. Así ha sido hasta ahora y asi parece seguir siendo en el excelente y completo trabajo publicado recientemente por P. Martín Aceña y F. Comin sobre la industria del INI con motivo del cincuentenario de esta, ya madura, institución.

Efectivamente, si se consideran los que, en mi opinión, constituyen los tres trabajos principales aparecidos hasta el momento sobre la evolución y actuación del INI: Schwartz y González; Myro y el que aqui nos ocupa; es interesante constatar cómo en cada uno de ellos puede percibirse el núcleo de interés intelectual que ha impulsado a sus autores. Así, el INI de Schwartz y González es, principal aunque no exclusivamente, un análisis de las concepciones de pensamiento económico que justifican y orientan el desarrollo en nuestro país de la empresa pública industrial de carácter concurrencial, lo que da motivo a sus autores para ejemplificar algunas de las limitaciones y disfunciones generales que, en su opinión, normalmente acompañan toda intervención pública en el mercado.

Por su parte, el INI de Myro es un estudio del papel específico cumplido por las empresas públicas en la configuración competitiva de sectores específicos, interesado principalmente en determinar las posibles características diferenciales de este tipo de empresas en término de su estrategia, eficiencia técnica y eficiencia económica.

Por último, el más reciente INI de Martin Aceña y Comin es, ante todo y 
principalmente, un trabajo de historia económica, lo que, al menos en la orientación seguida por los autores, implica y supone parte de lo anterior, y agrega un esfuerzo sistemático por captar la multidimensionalidad de la actuación del INI y su relación con la evolución de la economía española, tanto desde el punto de vista de su desarrollo como entidad corporativa, como desde la actuación de las empresas que lo componen.

Para ello, el completo trabajo de Martín Aceña y Comin sigue una perspectiva cronológica, basando su exposición en una delimitación de las distintas etapas diferenciables en la evolución del INI y tratando constantemente de enmarcar dicha evolución en la general seguida por la economía española en el mismo período. El análisis se articula principalmente a partir del propio Instituto y se basa en un detallado trabajo de recopilación y ordenación de bases documentales, contables y estadisticas desarrollado por los autores durante los últimos años en el marco de la Fundación Empresa Pública, cuyos resultados suponen una sólida base para futuras y deseables iniciativas.

La estrategia empleada por los autores tiene indudables aspectos positivos, en la medida que ayuda a ofrecer una imagen unitaria y coherente de la actuación del INI, permitiendo analizar detalladamente su interrelación con la evolución general de la economia española en las distintas fases de su desarrollo. Por otra parte, la distinción constantemente establecida entre el Instituto como corporación por una parte, y las empresas vinculadas al mismo, por otra parte, ayuda a diferenciar sus problemas específicos e introduce un aspecto esencial, y al que normalmente no se le ha concedido suficiente importancia, como es el análisis sistemático de la vinculación y relación organizativa entre las dos partes constitutivas del grupo.

Toda elección significa un coste y en este caso no podría ser menos. La elección del propio INI como elemento articulador del análisis y la adopción de un esquema temporal unitario como hilo conductor de la esposición, implica ciertos costes, evidentes especialmente a la hora de analizar la presencia y evolución especifica de las empresas del instituto en sectores o mercados determinados. Esto es debido a que dicha presencia no se adapta, en algunas ocasiones, al esquema temporal establecido y resulta muy dificil de analizar en todo su detalle sin un análisis específico del entorno económico y competitivo, nacional y/o internacional, en el que se produce.

De cualquier forma, más que limitaciones, estos aspectos pueden considerarse más bien como futuros temas a desarrollar a partir de la rica documentación acumulada por los autores, lo que sin duda les permitirá proseguir sus investigaciones, desarrollando un campo casi virgen en nuestro pais como es 
la historia económica de la empresa. Este tipo de investigaciones, híbridas entre la economia industrial y la historia económica, deberán de aportar una interesante información sobre la evolución de los esquemas organizativos de nuestras empresas y el desarrollo de la dinámica competitiva en mercados especificos lo que, sin duda, mejoraria la comprensión de la situación actual de nuestra industria.

La elevada variedad de temas incorporados en el estudio, en el que se incluyen todos los aspectos del funcionamiento del Instituto: creación y desaparición de empresas, inversiones, empleo, financiación, etc.; hace prácticamente una tarea imposible el intentar compendiar sus resultados. En cualquier caso, constituye una tentación dificil de renunciar el no referirse a algunos de los temas que, debido a su repetición, pueden considerarse como clásicos dentro de lo que se podría denominar como ugéneron de la empresa pública y que, en mi opinión, cobran nuevas perspectivas después del estudio que nos ocupa. Vaya por delante mi disculpa si en la descripción se mezcla en una dosis mayor de la debida la opinión del autor en estas líneas.

a) Sobre la "inevitabilidad» del INI: Existe una literatura que reivindica la etapa autárquica, en especial su segundo periodo (1951-58), como una fase destacada de la evolución de nuestra industria, en la medida en que en ella se generarian las bases del desarrollo posterior de la misma (1961-1974). Más allá de la constatación de que en un tiempo histórico continuo y unidireccional, todo hecho influye sobre los posteriores, esta posición cabe interpretarse como que la existencia de la propia autarquía, entre el conjunto de escenarios potencialmente posibles en aquellos momentos, fue positiva para nuestra industria, en el sentido de que el resultado posterior fue mejor que el derivado de otras posibles alternativas, liberalización e integración en la economía mundial, por ejemplo.

Esto último es lo que parecian pensar clara y consistentemente los artifices del INI. El mercado no se consideraba como un mecanismo suficiente para llegar a una adecuada asignación de recursos (p. 69) ${ }^{1}$ y con ciertas excepciones (el kgenio" del General Primo de Rivera), normalmente se evaluaba la anterior etapa económica como un «desastrew, detectándose en ella una, sin duda no muy conveniente, combinación de kabandonismo, desgana, incoherencia, sometimiento a la voluntad de los demás e intervencionismo extranjerow (cita tomada de Suanzes, p. 81). En este contexto resulta evidente la defensa frecuentemente hecha por el mismo Suanzes, y presente en la ley

Las acotaciones de píginas concretas se refieren a: Martin Aceria y Comin (1991) 
funcional del INI, sobre la indispensabilidad del Estado como promotor industrial y como agente inversor (p. 122).

Los autores del trabajo que nos ocupa no comparten esta posición, señalando cómo el INI no era la única alternativa posible para la industrialización, de igual forma que la autarquía no constituyó una condición necesaria para el crecimiento (p. 652). El atraso económico e industrial se relacionaría con otros mecanismos, y la pretendida «incapacidad» de la iniciativa privada implica una perversa y sesgada lectura de la historia económica anterior a la guerra civil, en la que realmente se detecta el inicio del tránsito hacia una economía moderna, industrial y urbana (pp. 66-67).

Aceptando básicamente esta argumentación, no creo que de ella pueda deducirse de una forma unilateral la «evitabilidad» del INI, aunque esto sea, quizá, un problema simplemente terminológico. Si bien el INI como institución específica, así como el tipo de intervención realizada por el Instituto especialmente en sus primeras etapas, seguramente resultan claramente "prescindibles» desde un punto de vista contrafactual para el desarrollo industrial de nuestro país, un análisis comparativo internacional del grado y distribución sectorial de la intervención pública directa en el sector industrial revela que la situación española es bastante similar a la existente en los paises de nuestro entorno. Esto puede interpretarse en el sentido de que, con independencia del INI como institución y de su orientación autárquica inicial, el resultado final de la intervención pública concurrencial ha seguido un modelo muy estandarizado en un plano internacional y se habría producido de una forma muy similar aun cuando el esquema institucional empleado hubiese sido distinto y su orientación diferente.

b) Sobre la "flexibilidad» del INI: Un aspecto frecuentemente mencionado, y al que los autores se refieren en diversas ocasiones, es la «flexibilidad» del INI para adaptarse a las diversas orientaciones de politica económica imperantes en cada momento, permitiéndole cumplir el papel exigido por la misma: industrialización sustitutiva de importaciones, subsidiaridad, compensación, reconversión, etc. (p. 613).

Sin embargo, esta aparente flexibilidad que lleva a pensar en reorientaciones constantes del Instituto ante los cambios de política económica, contrasta con el elevado grado de estabilidad del esquema sectorial de participaciones del Instituto a través de los años, presidentes y orientaciones. Si se considera la distribución sectorial de la inversión de las empresas, se constata una fuerte estabilidad de su distribución por sectores económicos, destacando un núcleo básico compuesto por el sector energético, minería y sidero-metalurgia que absorben en torno al $70 \%$ de las inversiones del grupo $(68,6 \%$ en 1963 ; 
$72,8 \%$ en 1989). Los cambios y reorientaciones experimentados por el INI, en sus distintas fases de evolución, aun siendo muy destacados han mantenido por lo tanto una especialización en los sectores básicos de la economía que se remonta casi a su propia creación.

c) Sobre la "ineficiencia" del INI: Entre los muchos aciertos del libro que comentamos, ocupa un lugar destacado un acierto por omisión (deliberada, sin duda), como es el no haber vuelto sobre el repetido tema de la ineficiencia de la empresa pública en su formulación habitual.

El estudio constata problemas del INI derivados de su estructura sectorial, de la composición y financiación de sus recursos, de sus esquemas organizativos $e$, incluso, de decisiones erróneas de inversión, propias o impuestas; pero en ningún caso se traspasa el frecuentemente transgredido límite que lleva a inferir condiciones de ineficiencia de sus empresas por el simple y mero hecho de ser públicas.

De hecho, del análisis de las características que normalmente se interpretan como exponentes de la «ineficiencia» de las empresas públicas se puede deducir una pauta general que normalmente las genera: la contradicción entre los objetivos establecidos o impuestos al Instituto y los medios generados o facilitados para su cumplimiento. Ya sea referido a su etapa autárquica, con las contradicciones evidentes entre los objetivos técnicos y productivos derivados de los planes regeneradores de Suanzes, y los medios económicos y financieros puestos a su disposición para dicho fin (cap. 3, p. 125); en la etapa «desarrollista», con el doble objetivo incongruente de subsidiaridad y una mayor recurrencia financiera a fondos obtenidos del mercado (cap. 4, p. 418; Boyer, M. (1975)); o en la etapa "compensadora», imponiéndole un mantenimiento o, incluso, aumento de empleo, un crecimiento de sus inversiones y la absorción de empresas en crisis a la par que una mejora de resultados (cap. 5); el Instituto ha estado frecuentemente sometido a una fuerte tensión entre los objetivos, implícitos o explícitos, que se le exigen y los medios necesarios para su posible cumplimiento ${ }^{2}$.

En esta perspectiva histórica, por lo tanto, cualquier cambio que suponga una mayor autonomía, tanto en la formulación de actividades y estrategias como en la captación de los medios necesarios para su cumplimiento, supone una evidente y necesaria clarificación en la interpretación de los resultados del Instituto.

Los cambios recientes, introducidos a partir de la Ley de Presupuestos de

2 En muchos casos el cumplimiento habria sido imposible aun sin ningún tipo de restricción, ya que suponian objetivos incompatibles. 
1988, parecen avanzar en este sentido, otorgando al Instituto plena personalidad jurídica propia y permitiéndole una mayor autonomía para formular sus objetivos bajo el principio general de rentabilidad como guia de sus actuaciones. El desdoblamiento de la entidad en dos partes, agrupando en una subsección de la misma, aquellas iniciativas mantenidas por objetivos generales de política económica y, por lo tanto, subsidiados explícitamente, clarificaría totalmente sus actuaciones, permitiendo una inmediata referencia respecto a la eficiencia de la otra subsección, que operaría bajo normas homogéneas de mercado. Evidentemente, esto supondría también cambios organizativos que normalmente no se están teniendo en cuenta, ya que la estructura organizativa y de control para las dos subsecciones no puede ser exactamente la misma, requiriendo las actividades reguladas un sistema diferenciado de canalización de la información e imposición de objetivos.

En último término, con su plena entrada en el mercado estaríamos llegando a un personal "final de la historia», en este caso referido al INI. Después de una tortuosa y esforzada evolución se llegaría a tener una corporación de empresas de capital público que se comportasen como privado. Sin embargo, la propia historia del INI y sus transformaciones nos aconseja ser cautos en nuestras conclusiones, no desechando cambios futuros en cualquier dirección, incluso circulares. No en vano la Ley 37/1988 esconde en su interior el dilema irresoluble que ha marcado la evolución de la institución al considerar que los objetivos del INI deben de ser recogidos por el «principio de rentabilidad y eficiencia sin perjuicio de atender el cumplimiento de objetivos de interés general que puedan asignársele». Nada mejor como resumen de la historia pasada y futura del INI.

\section{REFERENCIAS}

MARTIN ACENA, P. y COMín, F. (1991): INI: 50 años de industrialización en España, Espasa Calpe.

MYRO, R. (1980): El INI en la industria española: especialización sectorial, eficiencia económica y rentabilidad (Tesis Doctoral), Universidad Complutense de Madrid.

SCHWARTZ, P. y GONZÁleZ, M. J. (1978): Una historia del Instituto Nacional de Industria (1941-1976), Tecnos.

BOYER, M. (1975): “La empresa pública en la estrategia industrial española: el INI», Información Comercial Española, núm. 500. 